\title{
Subtenon triamcinolone injection for postoperative cystoid macular edema associated with tafluprost
}

This article was published in the following Dove Press journal:

Clinical Ophthalmology

23 July 2013

Number of times this article has been viewed

\section{Kazuki Matsuura' \\ Ryu Uotani² \\ Yuki Terasaka'}

'Nojima Hospital, Tottori, Japan;

${ }^{2}$ Tottori University, Tottori, Japan
Correspondence: Kazuki Matsuura Nojima Hospital, 27।4-I Sesaki-machi, Kurayoshi City, Tottori 682-0863, Japan Email i-mnys200I@za.ztv.ne.jp; matsu224@ncn-k.net
Purpose: We report the successful treatment of a case of cystoid macular edema (CME) associated with topical tafluprost, which was accompanied by serous retinal detachment (SRD).

Case: A 78-year-old woman underwent intraocular lens suture surgery, including anterior vitreous cutting, for crystalline lens dislocation in the right eye. Tafluprost was initiated 12 weeks after surgery. Intraocular pressure (IOP) was controlled at $10-14 \mathrm{mmHg}$. Visual acuity remained at 20/40-30/40. However, the patient complained of blurred vision (20/200) 9 months after surgery. CME accompanied by SRD was identified by optical coherence tomography (OCT) and treated with subtenon triamcinolone injection. Visual acuity rapidly increased to 20/50, and the volume of SRD decreased in a few days. Discontinuation of tafluprost and initiation of diclofenac eye drops improved visual acuity to 20/40 and resulted in improved OCT findings within a few weeks. Three months after injection, tafluprost was resumed along with diclofenac. No recurrence of CME occurred over the following 3 months, and IOP was controlled at 10-15 $\mathrm{mmHg}$.

Conclusion: SRD is considered to be a symptom of treatment-resistant CME, which may lead to poor visual acuity after recovery. In such cases, subtenon triamcinolone injection should be strongly considered at an early stage.

Keywords: tafluprost, cystoid macular edema, serous retinal detachment, subtenon triamcinolone

\section{Introduction}

Cystoid macular edema (CME) has been reported in association with the use of latanoprost, travoprost, and bimatoprost. ${ }^{1,2}$ These drugs are ocular hypotensive lipids, and their side effects can be expected to be somewhat similar. In this report, we describe a case of CME associated with tafluprost. Optical coherence tomography (OCT) revealed typical CME appearance with serous retinal detachment (SRD). The patient was successfully treated with subtenon triamcinolone injection. To our knowledge, this is the first report of CME associated with tafluprost.

\section{Case report}

A 78-year-old woman, who had a history of chronic bronchitis, was under observation for glaucoma with use of tafluprost. Intraocular pressure (IOP) was controlled at 13-16 mmHg without any tafluprost side effects.

The patient underwent intraocular lens (IOL) suture surgery, including anterior vitreous cutting, for crystalline lens dislocation in the right eye. Tafluprost was resumed 12 weeks after surgery. Intraocular pressure (IOP) was controlled at 10-14 $\mathrm{mmHg}$. Visual acuity remained at 20/40-30/40. However, 9 months after the surgery, the 
patient complained of blurred vision (20/200), and CME accompanied by SRD was identified with OCT (Figure 1A). After injection of subtenon triamcinolone, visual acuity rapidly recovered to $20 / 50$, and the SRD lost its volume in a few days (Figure 1B). Discontinuation of tafluprost and initiation of diclofenac eye drops improved visual acuity to 20/40 and OCT showed improvements within a few weeks (Figure 1C and D). An IOP spike after injection of subtenon triamcinolone was observed. Because IOP was above $20 \mathrm{mmHg}$, we resumed treatment with diclofenac eye drops and tafluprost 3 months after injection, as we considered that the damage to the blood-aqueous barrier would be protracted. No recur-

A

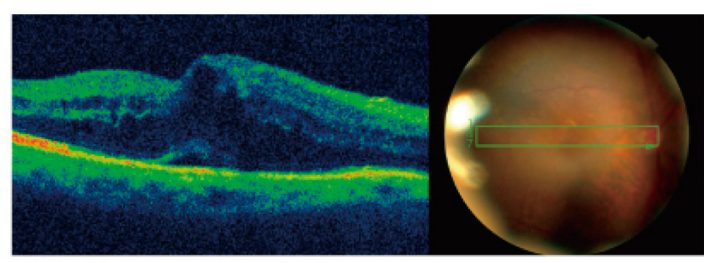

B

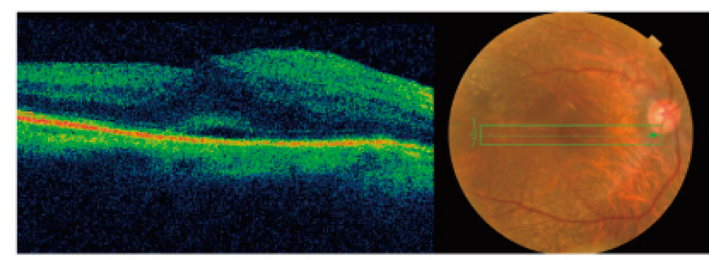

C

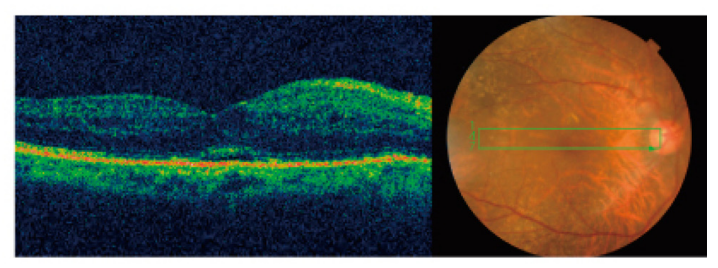

D

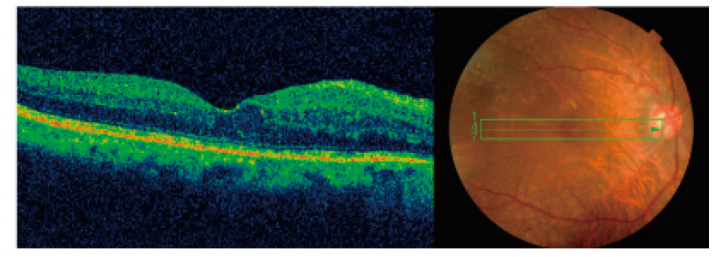

$\mathbf{E}$

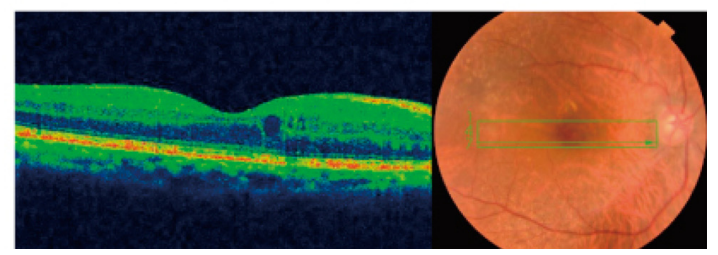

Figure I Vertical sections of optical coherence tomography

Notes: (A) CME accompanied by dome-shaped SRD with large base (November 19, 2012). (B) Visual acuity quickly improved (20/50) and SRD lost its volume in a few days after treatment with an injection of subtenon triamcinolone (November 21, 20I2). (C) Small SRD remained just beneath the fovea (November 28, 20I2). (D) CME and SRD disappeared and visual acuity improved to 20/40 I month after injection (December 2I, 20I2). (E) No recurrence of the CME occurred (May I4, 20I3). Abbreviations: CME, cystoid macular edema; SRD, serous retinal detachment. rence of CME occurred during the following 3 months, and IOP was controlled at $10-15 \mathrm{mmHg}$ (Figure 1E).

\section{Discussion}

Tafluprost, like other prostaglandin analogs, exerts its effects on prostaglandin F receptors to reduce IOP. Several clinical studies have assessed the efficacy of tafluprost and reported that it was equivalent to the efficacy of latanoprost. ${ }^{3}$ Furthermore, some recent studies have suggested that tafluprost has direct neuroprotective effects. Mayama et al found that topical tafluprost enhanced optic nerve head blood flow in naïve eyes without significant IOP reduction. ${ }^{4}$ Side effects of tafluprost, such as deepening of the eyelid sulcus and increased eyelid pigmentation, have been reported to be similar to those of other prostaglandin eye drops..$^{5}$ The incidence of deepening of the eyelid sulcus has been shown to be lower with tafluprost than with latanoprost, travoprost, or bimatoprost. ${ }^{5}$ Liang et al indicated that the benzalkonium chloride (BAK) preservative is the primary cause of cytotoxicity due to prostaglandin analogs, given that BAK-free products had minimal impact on the corneoconjunctival surface. ${ }^{6}$ Uusitalo et al evaluated the pharmacokinetics and safety profiles of preservativefree and preservative-containing tafluprost; although the incidence of ocular hyperemia was similar for both forms of tafluprost, it was less severe with preservative-free tafluprost. ${ }^{7}$ Prostaglandin analogs have been shown to cause CME after cataract surgery. Miyake et al reported that the preservatives in prostaglandin eye drops have a greater influence on the development of CME than the base compound. ${ }^{8}$ There are many reports of CME associated with latanoprost, ${ }^{9-19}$ which contains a relatively high BAK concentration $(0.02 \%)$, but there are few reports of CME associated with BAK-free travoprost. BAK-free tafluprost became available in Western countries in 2012; the Japanese product contains a very low concentration of BAK $(0.001 \%)$. To our knowledge, this is the first report of CME associated with tafluprost.

Risk factors for CME due to prostaglandin eye drops include a history of glaucoma surgeries, aphakia, complicated cataract surgery, scleral buckling, and vitrectomy, as well as a history of uveitis and other retinal diseases. It is rare for patients without risk factors to develop CME. ${ }^{9-15}$ Wand et al ${ }^{12}$ reported that two of 38 high-risk cases (5.3\%) developed clinical CME. Fukuichi et $\mathrm{al}^{16}$ found no cases of clinical CME among 68 patients without any of the reported risk factors. In cases without known risk factors, CME can appear within 2-3 months after surgery, ${ }^{17,18}$ while in high-risk cases, CME can develop several years after surgery. ${ }^{9,11-13,15,20}$ In the former, CME may develop immediately after surgery because 
of temporary damage to the blood-aqueous barrier, while in cases with known risk factors, the damage to the bloodaqueous barrier is protracted, resulting in a continuation of conditions that can lead to CME in the long term. In the case reported here, anterior vitreous cutting and the IOL suture surgery were performed for crystalline lens dislocation; thus, CME accompanied with SRD occurred 9 months after surgery.

As leakage from retinal capillaries increases, traction on the inner and outer segments of the fovea produces a small, pointed retinal detachment with a small base. When the barrier function of external limiting membrane breaks down, the serous RD enlarges and changes into a dome-shaped retinal detachment with a large base. ${ }^{21}$

Tsujikawa et al reported that the outer retinal discontinuity on the external surface of the retina does not necessarily lead to poor vision. ${ }^{21}$ However, even after complete resolution of the macular edema and SRD, diffuse disorganization of the outer photoreceptor layer beneath the fovea often results in poor visual acuity. In addition, a dome-shaped retinal detachment sometimes accompanies a focal defect of the outer segment of the photoreceptors above SRD. ${ }^{21}$

Several treatment options are available for prostaglandininduced CME, including non-steroidal anti-inflammatory drugs (NSAIDs), steroids, dorzolamide hydrochloride eye drops, and oral acetazolamide; however, in many cases, recovery can take a month or more. ${ }^{11-13,17,19,22}$ We previously reported two cases in which travoprost- and latanoprost-induced CME was successfully treated in a few days with subtenon injection of triamcinolone. ${ }^{23}$ Subtenon triamcinolone injection is considered to be effective and is the standard treatment for CME due to diabetic retinopathy, retinal vein occlusion, uveitis, and other conditions. Therefore, in this case, we employed subtenon triamcinolone injection immediately after diagnosis, anticipating a quick recovery from CME and a subsequently minimized irreversible disruption in the sensory retina.

We reported two cases in which CME did not recur for more than 3 years after resumption of prostaglandin eye drops. ${ }^{23}$ The first case was CME associated with travoprost following uneventful cataract surgery. The second case was CME associated with latanoprost after anterior vitreous cutting and IOL suture. Diclofenac was used after resumption of latanoprost in the second case. Wand and Gaudio ${ }^{20}$ reported two cases in which CME treated with NSAIDs did not recur after unoprostone and bimatoprost treatments were resumed. Furthermore, Wand et al reported one case in which CME did not recur after latanoprost treatment was resumed. ${ }^{12}$ Callanan et $\mathrm{al}^{11}$ reported one case in which CME that was not treated with NSAIDs recurred after resuming treatment with latanoprost. Prostaglandin has no systemic side effects and is currently the most effective drug in the form of eye drops.

Beta-blockers were not chosen as treatment in this case because of the patient's history of bronchitis, nor brimonidine, which was not commercially available until May 2012 in Japan. Thus, tafluprost use was resumed postoperatively, considering that the patient had been well-controlled and without tafluprost side effects before surgery. Although we believe the risk of CME would be reduced by using tafluprost along with NSAIDs, the patient was informed of the necessity of careful observation.

When possible, the use of prostaglandin eye drops can be resumed after a certain period of time after recovery, under careful observation. In certain cases, the concomitant use of NSAIDs and prostaglandin eye drops can be greatly beneficial to patients.

\section{Conclusion}

We have reported a case of CME associated with tafluprost and accompanied by SRD. SRD was considered to be a symptom of treatment-resistant CME, which can lead to poor visual acuity after recovery. In such cases, subtenon triamcinolone injection should be considered at an early stage.

\section{Disclosure}

The authors report no conflicts of interest in this work.

\section{References}

1. Arcieri ES, Santana A, Rocha FN, Gaupo GL, Costa VP. Blood-aqueous barrier changes after the use of prostaglandin analogues in patients with pseudophakia and aphakia: a 6-month randomized trial. Arch Ophthalmol. 2005;123(2):186-192.

2. Agange N, Mosaed S. Prostaglandin-induced cystoid macular edema following routine cataract extraction. J Ophthalmol. 2010;(2010).

3. Liu Y, Mao W. Tafluprost once daily for treatment of elevated intraocular pressure in patients with open-angle glaucoma. Clin Ophthalmol. 2013;7: $7-14$.

4. Mayama C, Ishii K, SaekiT, Ota T, TomidokoroA, Araie M. Effects of topical phenylephrine and tafluprost on optic nerve head circulation in monkeys with unilateral experimental glaucoma. Invest Ophthalmol Vis Sci. 2010;51(8):4117-4124.

5. Inoue K, Shiokawa M, Wakakura M, Tomita G. Deepening of the upper eyelid sulcus caused by 5 types of prostaglandin analogs. J Glaucoma. Epub August 29, 2012.

6. Liang H, Baudouin C, Labbe A, Riancho L, Brignole-Baudouin F. Conjunctiva-associated lymphoid tissue (CALT) reactions to antiglaucoma prostaglandins with or without BAK-preservative in rabbit acute toxicity study. PLoS One. 2012;7:e33913.

7. Uusitalo H, Kaarniranta K, Ropo A. Pharmacokinetics, efficacy, and safety profiles of preserved and preserve-free tafluprost in healthy volunteers. Acta Ophthalmol Suppl (Oxf). 2008;242:7-13.

8. Miyake K, Ota I, Ibaraki N, et al. Enhanced disruption of the bloodaqueous barrier and the incidence of angiographic cystoid macular edema by topical timolol and its preservative in early postoperative pseudophakia. Arch Ophthalmol. 2001;119(3):387-394. 
9. Ayyala RS, Cruz DA, Margo CE, et al. Cystoid macular edema associated with latanoprost in aphakic and pseudophakic eyes. Am J Ophthalmol. 1998;126(4):602-604.

10. Moroi SE, Gottfredsdottir MS, Schteingart MT, et al. Cystoid macular edema associated with latanprost therapy in a case of patients with glaucoma and ocular hypertension. Ophthalmology. 1999;106(5): 1024-1029.

11. Callanan D, Fellman RL, Savage JA. Latanoprost-associated cystoid macular edema. Am J Ophthalmol. 1998;126(1):134-135.

12. Wand M, Gaudio AR, Shields MB. Latanoprost and cystoid macular edema in high-risk aphakic or pseudophakic eyes. J Cataract Refract Surg. 2001;27(9):1397-1401.

13. Tokunaga T, Kashiwagi K, Saito J, et al. A case of cystoid macular edema associated with latanoprost ophthalmic solution. Jpn J Ophthalmol. 2002;46(6):656-659.

14. Jäger M, Jonas JB. Cytoid macular edema associated with latanoprost therapy in a pseudophakic vitrectomized patient after removal of silicone oil endotamponade. Eur J Ophthalmol. 2003;13(2): 221-222.

15. Watanabe K, Hayasaka S, Hayasaka Y, Nagaki Y, Watanabe K. Cystoid macular edema associated with latanoprost use in a pseudophakic eye with a history of surgical complications. Jpn J Ophthalmol. 2003;47(1): $110-112$.
16. Fukuichi M, Chiba T, Abe K, et al. Cystoid macular edema associated with topical latanoprost in glaucomatous eyes with a normally functioning blood-ocular barrier. J Glaucoma. 2001;10(3):233-236.

17. Altintas O, Yüksel N, Karabas VL, Dermirci G. Cystoid macular edema associated with latanoprost after uncomplicated cataract surgery. Eur J Ophthalmol. 2005;15(1):158-161.

18. Yeh PC, Ramanathan S. Latanoprost and clinically significant cystoid macular edema after uneventful phacoemulsification with intraocular lens implantation. J Cataract Refract Surg. 2002;28(10):1814-1818.

19. Carrillo MM, Nicolela MT. Cystoid macular edema in a low-risk patient after switching from latanoprost to bimatoprost. Am J Ophthalmol. 2004;137(5):966-968.

20. Wand M, Gaudio AR. Cystoid macular edema associated with ocular hypotensive lipids. Am J Ophthalmol. 2002;133(3):403-405.

21. Tsujikawa A, Sakamoto A, Ota M, et al. Serous retinal detachment associated with retinal vein occlusion. Am J Ophthalmol. 2010;149(2): 291-301.

22. Esquenazi S. Cystoid macular edema in a pseudophakic patient after switching from latanoprost to BAK-free travoprost. J Ocul Pharmacol Ther. 2007;23(6):567-570.

23. Matsuura K, Sasaki S, Uotani R. Successful treatment of prostaglandin-induced cystoid macular edema with subtenon triamcinolone. Clin Ophthalmol. 2012;6:2105-2108.
Clinical Ophthalmology

\section{Publish your work in this journal}

Clinical Ophthalmology is an international, peer-reviewed journal covering all subspecialties within ophthalmology. Key topics include: Optometry; Visual science; Pharmacology and drug therapy in eye diseases; Basic Sciences; Primary and Secondary eye care; Patient Safety and Quality of Care Improvements. This journal is indexed on

\section{Dovepress}

PubMed Central and CAS, and is the official journal of The Society of Clinical Ophthalmology (SCO). The manuscript management system is completely online and includes a very quick and fair peer-review system, which is all easy to use. Visit http://www.dovepress.com/ testimonials.php to read real quotes from published authors. 